\title{
Effect of the interaction between soil moisture and growth stage of weeds on the efficacy of herbicides applied at different doses
}

\author{
Wpływ współdziałania wilgotności gleby i fazy rozwojowej chwastów \\ na skuteczność herbicydów stosowanych w zróżnicowanych dawkach
}

\author{
Renata Kieloch*, Krzysztof Domaradzki
}

\begin{abstract}
Summary
The pot experiment under controlled environment was carried out to evaluate the influence of the interaction between soil moisture (60 and 30\%) and growth stage (2-4 and 6-8 leaves) of Anthemis arvensis L. and Papaver rhoeas L. on the efficacy of herbicides. Under optimal conditions (growth stage of 2-4 leaves and soil moisture 60\%), high efficacy for both doses of the mixture 2,4-D + florasulam and full dose of the mixture 2,4-D + dicamba was observed. Dose reduction of the second mixture contributed to poorer weed control. Low soil moisture and advanced growth stage of weeds decreased the efficacy of the mixture 2,4-D + florasulam against $P$. rhoeas. However, $A$. arvensis at the growth stage of 2-4 leaves was efficiently controlled under low soil moisture conditions. The mixture 2,4-D + dicamba applied under optimal conditions was efficient only against $A$. arvensis. Regardless of weed species, a decrease of herbicide efficacy for reduced dose was noted under above conditions. Application of the mixture 2,4-D + dicamba at the growth stage of 6-8 leaves resulted in poor herbicide effect despite the soil moisture. Water deficit in soil also significant decreased the herbicide efficacy.
\end{abstract}

Key words: herbicides; doses; efficacy; soil moisture; weeds growth stage; interaction

\begin{abstract}
Streszczenie
Badania wykonano w warunkach kontrolowanych w celu oceny wpływu interakcji wilgotności gleby (60 i $30 \%$ ) i fazy rozwojowej (2-4 i 6-8 liści) Anthemis arvensis L. i Papaver rhoeas L. na skuteczność herbicydów stosowanych w dawce zalecanej i obniżonej o 50\%. W warunkach optymalnych (faza 2-4 liści i wilgotność gleby 60\%) osiągnięto wysoką skuteczność obu dawek mieszaniny 2,4-D + florasulam oraz pełnej dawki mieszaniny 2,4-D + dikamba. Obniżenie dawki mieszaniny 2,4-D + dikamba przyczyniło się do słabszego zwalczania chwastów. Niska wilgotność gleby i zaawansowana faza rozwojowa chwastów spowodowała spadek efektywności mieszaniny 2,4-D + florasulam w stosunku do $P$. rhoeas, natomiast $A$. arvensis był skutecznie niszczony w warunkach niskiej wilgotności gleby, jedynie gdy rośliny znajdowały się w fazie 2-4 liści. Mieszanina 2,4-D + dikamba stosowana w optymalnych warunkach była skuteczna jedynie w niszczeniu $A$. arvensis. Niezależnie od gatunku chwastu, w powyższych warunkach nastąpił spadek skuteczności mieszaniny 2,4-D + dikamba stosowanej w dawce zredukowanej. Aplikacja mieszaniny 2,4-D + dikamba na rośliny w fazie 6-8 liści skutkowała słabym efektem bez względu na wilgotność gleby. Do znacznego spadku skuteczności przyczynił się również deficyt wody w glebie.
\end{abstract}

Słowa kluczowe: herbicydy; dawki; skuteczność; wilgotność gleby; faza rozwojowa chwastów; interakcja

\footnotetext{
Instytut Uprawy Nawożenia i Gleboznawstwa - Państwowy Instytut Badawczy

Zakład Herbologii i Technik Uprawy Roli

Orzechowa 61, 50-540 Wrocław

*correspondig author: r.kieloch@iung.wroclaw.pl
} 


\section{Wstęp / Introduction}

Od dnia 01.01.2014 roku w krajach członkowskich Unii Europejskiej w trosce o środowisko naturalne oraz zdrowie ludzi i zwierząt zaczęła obowiązywać ustawa o integrowanej ochronie roślin, której głównym celem jest zminimalizowanie stosowania pestycydów. Badania nad stosowaniem obniżonych dawek herbicydów są prowadzone w Polsce już od połowy lat dziewięćdziesiątych ubiegłego wieku. Wykazały one, że dawkę środka chwastobójczego można zredukować nawet o połowę, bez znaczącego spadku skuteczności chwastobójczej oraz strat w plonach (Domaradzki i Rola 2001; Urban i wsp. 2011). Obowiązująca do niedawna ustawa nie pozwalała na stosowanie środków ochrony roślin niezgodnie $\mathrm{z}$ zaleceniami zawartymi w etykiecie. Rozporządzenie Parlamentu Europejskiego i Rady (WE) nr 1107/2009 dopuszcza taką możliwość, jednak należy mieć na uwadze, że aplikacja danego środka w dawce niższej niż zaleca producent wymaga wiedzy dotyczącej jego działania w zróżnicowanych warunkach. Powszechnie znany jest fakt, że efekt działania herbicydu jest w znacznym stopniu determinowany przez warunki środowiskowe oraz stan zachwaszczenia, w tym fazę rozwojową chwastów. Czynniki te wpływają na: pobieranie, przemieszczanie i rozkład herbicydu w roślinie, a w konsekwencji jego efekt chwastobójczy (Levene i Owen 1995; Petersen i Hurle 2001; Kieloch i Domaradzki 2011).

Wykonane dotychczas badania w tym zakresie obejmowały wpływ niekorzystnych warunków środowiska na działanie herbicydów, gdy stosowano je na chwasty we wczesnych fazach rozwojowych. Brak jest natomiast informacji odnośnie ich skuteczności, gdy zarówno czynnik środowiskowy, jak również faza rozwojowa chwastu nie sprzyjają działaniu zastosowanego środka.

Celem badań była ocena wpływu interakcji fazy rozwojowej chwastów i wilgotności gleby na skuteczność herbicydów aplikowanych w dawkach: zalecanej i zredukowanej.

\section{Materiały i metody / Materials and methods}

Badania wykonano w Zakładzie Herbologii i Technik Uprawy Roli we Wrocławiu w warunkach kontrolowanych, w komorach klimatycznych. Roślinami testowymi były Anthemis arvensis L. i Papaver rhoeas L. W doświadczeniu określono wpływ dwóch poziomów wilgotności gleby, tj. 60 i 30\% na działanie herbicydów, a w obrębie każdego $\mathrm{z}$ nich uwzględniono dwie fazy rozwojowe chwastów: 2-4 (BBCH 12-14) i 6-8 liści (BBCH 16-18). Temperatura powietrza wynosiła $20^{\circ} \mathrm{C}$ w dzień i $10^{\circ} \mathrm{C}$ w nocy, a fotoperiod 14 godzin dnia i 10 godzin nocy. Doświadczenie założono w układzie kompletnej randomizacji w trzech powtórzeniach.

Nasiona chwastów wysiano na głębokość $0,5 \mathrm{~cm}$ do doniczek o średnicy $8 \mathrm{~cm}$ wypełnionych odpowiednio przygotowaną glebą brunatną zawierającą $1,77 \%$ materii organicznej, o $\mathrm{pH} 6,8$. W tym celu, przed przystąpieniem do siewu, glebę oczyszczono z kamieni i resztek roślinnych, a następnie przesiano przez sito o średnicy oczek $2 \mathrm{~mm}$. Bezpośrednio przed założeniem doświadczenia gle- bę wysuszono w temperaturze $105^{\circ} \mathrm{C}$ do stanu powietrznie suchego. Do każdej z doniczek odważono 400 g gleby oraz dodano $240 \mathrm{~g}$ lub $120 \mathrm{~g}$ wody w zależności od poziomu badanego czynnika, aby osiągnąć odpowiednio $60 \%$ (gleba dobrze uwilgotniona) lub 30\% (gleba sucha) wilgotności wagowej gleby. Wilgotną glebę w każdej doniczce dokładnie wymieszano w celu równomiernego rozprowadzenia wody w masie stałej gleby. Doniczki codziennie ważono, a na podstawie ubytku masy całej doniczki ustalono ilość wody konieczną do podlewania tak, aby osiągnąć masę ustaloną w momencie założenia doświadczenia.

W doświadczeniu uwzględniono dwa herbicydy: 1. Mieszanina 2,4-D + florasulam (Mustang $306 \mathrm{SE}$ ). 2. Mieszanina 2,4-D + dikamba (Aminopielik D $450 \mathrm{SL}$ ). Każdy z nich zastosowano w dwóch dawkach (zalecanej oraz obniżonej o połowę), które wynosiły dla mieszaniny 2,4-D + florasulam: $180+3,75 \mathrm{~g} /$ ha i $90+1,875 \mathrm{~g} / \mathrm{ha}$, a dla mieszaniny 2,4-D + dikamba: $1252,5+97,5 \mathrm{~g} / \mathrm{ha}$ i $626,25+48,75 \mathrm{~g} / \mathrm{ha}$.

Dzień przed planowanym opryskiwaniem wykonano przerywkę, zostawiając po 4 rośliny w każdej z doniczek. Aplikację herbicydów przeprowadzono w komorze opryskowej z ruchomą dyszą (TeeJet XR 11003-VS) z ciśnieniem $200 \mathrm{kPa}$ i wydatkiem cieczy użytkowej $250 \mathrm{l} / \mathrm{ha}$. Po upływie trzech tygodni od zabiegu zebrano rośliny, a następnie ustalono świeżą masę części nadziemnych chwastów.

Na obiektach traktowanych herbicydami, na podstawie ubytku świeżej masy chwastów pod wpływem działania stosowanych środków określono ich skuteczność, którą wyrażono w \%. Obliczenia statystyczne wykonano na wyżej wymienionych wartościach zniszczenia chwastów uprzednio przekształconych według wzoru Blissa. Obliczenia wykonano dla układu dwuczynnikowego, gdzie jednym z czynników była kombinacja wilgotność glebyn $\times$ faza rozwojowa, natomiast drugim czynnikiem była dawka herbicydu.

\section{Wyniki i dyskusja / Results and discussion}

Mieszanina 2,4-D z florasulamem skutecznie zwalczała A. arvensis, gdy zabieg wykonano w warunkach optymalnych, tj. na rośliny we wczesnej fazie rozwojowej (2-4 liście), rosnące na glebie dobrze uwilgotnionej (60\%) (rys. 1). Badany środek wykazał zbliżony efekt chwastobójczy dla obu dawek, który kształtował się na poziomie 90-93\%. Aplikacja na rośliny starsze, tj. w fazie 6-8 liści, skutkowała spadkiem efektywności herbicydu do poziomu $78 \%$ oraz wystąpieniem istotnych różnic pomiędzy dawkami. Mieszanina 2,4-D + florasulam w dawce obniżonej zwalczała $A$. arvensis w $67 \%$. W warunkach niedostatecznego uwilgotnienia gleby, tj. 30\%, badany środek osiągnął zadowalający efekt chwastobójczy (87\%) w stosunku do A. arvensis jedynie po aplikacji dawki zalecanej na rośliny we wczesnej fazie rozwojowej. Znaczący spadek efektywności obu dawek środka następował w starszej fazie rozwojowej roślin. Mieszanina w dawce zalecanej ograniczała masę roślin w $78 \%$, podczas gdy obniżona o połowę działała zaledwie w 49\%. Większe różnice w skuteczności pomiędzy badanymi dawkami zaobserwowano w przy- 
padku bardziej zaawansowanej fazy rozwojowej. Młode rośliny $P$. rhoeas (2-4 liście) rosnące na glebie dobrze uwilgotnionej były skutecznie niszczone przez mieszaninę 2,4-D z florasulamem zastosowaną zarówno w dawce zalecanej, jak i obniżonej, jednak analiza statystyczna wykazała istotność różnic $\mathrm{w}$ ich działaniu. W przypadku roślin bardziej wyrośniętych zanotowano mniejszą wrażliwość na herbicyd aplikowany w dawce pełnej oraz znaczący spadek efektywności środka $\mathrm{w}$ dawce zredukowanej w porównaniu $\mathrm{z}$ zalecaną (rys. 2). W warunkach niedostatecznego uwilgotnienia gleby nie osiągnięto zadowalającego efektu chwastobójczego, nawet dla dawki pełnej stosowanej na rośliny młode. Podobnie niską skuteczność zaobserwowano w przypadku aplikacji na chwasty bardziej wyrośnięte. Skuteczność herbicydu stosowanego $\mathrm{w}$ dawce zalecanej na rośliny zarówno młode, jak i starsze była zbliżona do tej, którą osiągnięto na glebie wilgotnej, gdy zabieg wykonano w fazie 6-8 liści. Po aplikacji dawki obniżonej nastąpił spadek efektywności środka, gdy zabieg wykonano zarówno na rośliny w fazie 2-4, jak również 6-8 liści. Większe różnice między dawkami zanotowano w przypadku roślin bardziej wyrośniętych.

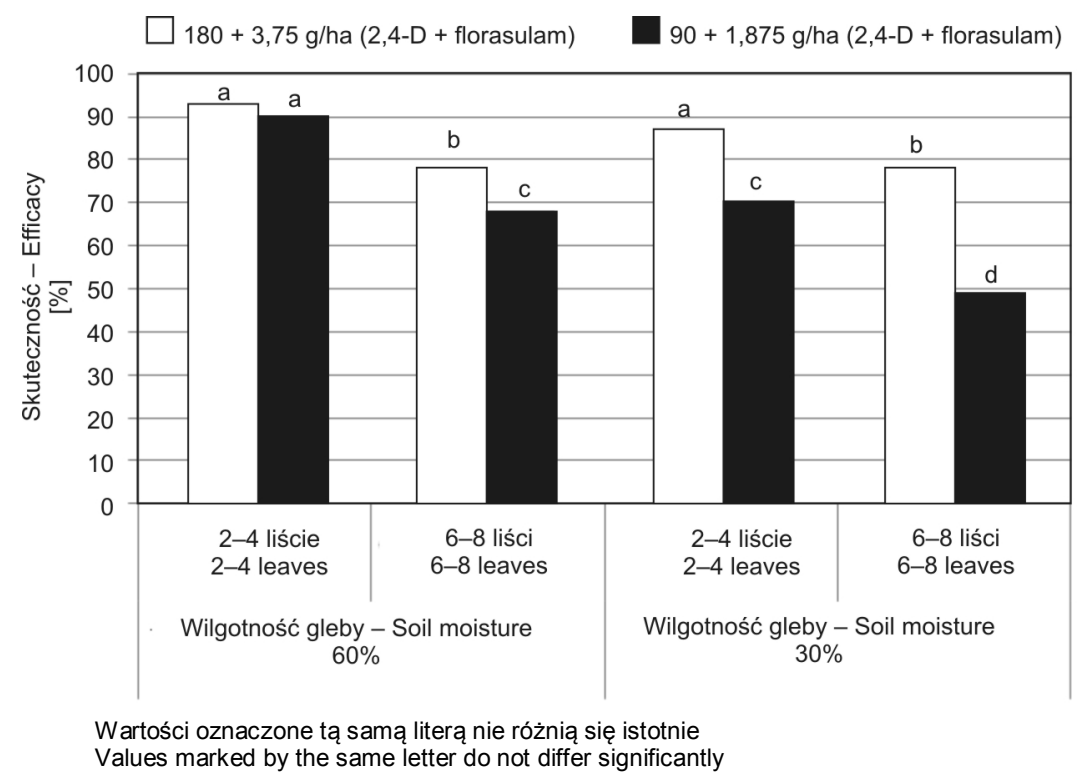

Rys. 1. Wpływ współdziałania wilgotności gleby i fazy rozwojowej na skuteczność mieszaniny 2,4-D + florasulam w zwalczaniu A. arvensis

Fig. 1. Influence of interaction between soil moisture and growth stage on the efficacy of the mixture 2,4-D + florasulam against A. arvensis

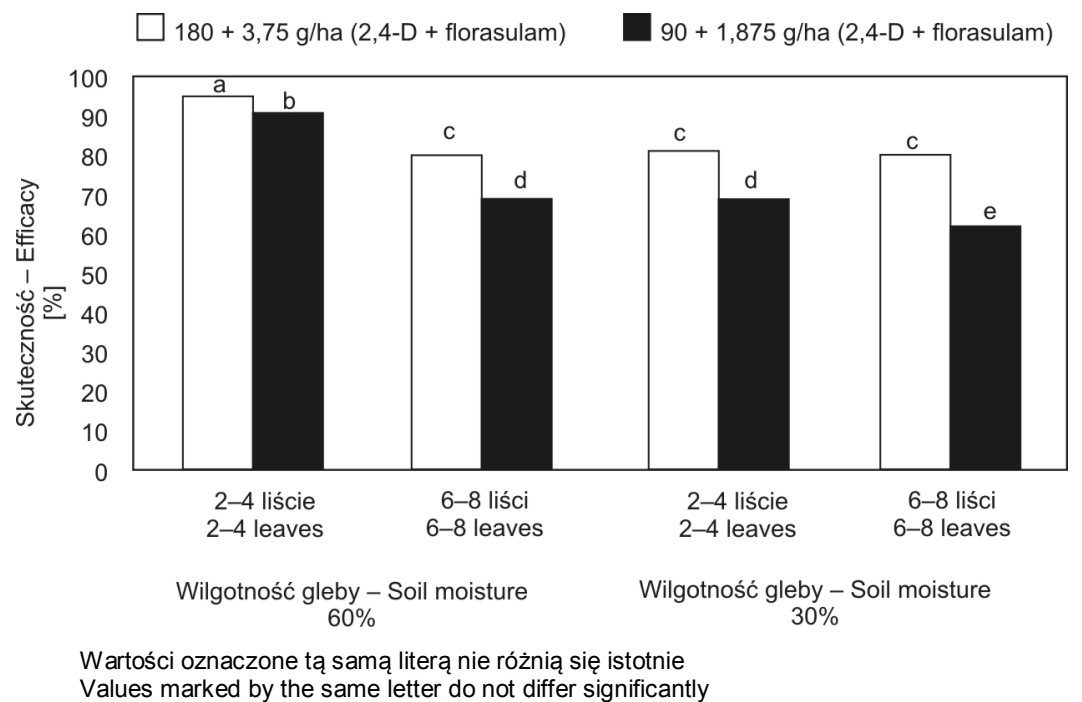

Rys. 2. Wpływ współdziałania wilgotności gleby i fazy rozwojowej na skuteczność mieszaniny 2,4-D + florasulam w zwalczaniu $P$. rhoeas

Fig. 2. Influence of interaction between soil moisture and growth stage on the efficacy of the mixture 2,4-D + florasulam against P. rhoeas 
Mieszanina 2,4-D + dikamba wykazała wysoką skuteczność (86\%) jedynie wtedy, gdy aplikowano ją w dawce zalecanej na młode rośliny $A$. arvensis rosnące na glebie wilgotnej (rys. 3). Obniżenie dawki środka spowodowało znaczący spadek jego efektywności do poziomu 71\%. Najsilniejsze ograniczenie skuteczności działania herbicydu (36-42\%) w odniesieniu do tego gatunku zaobserwowano $\mathrm{u}$ roślin starszych. W tych warunkach nie wykazano istotnych różnic między dawkami środka. Słabe uwilgot- nienie gleby przyczyniło się do znacznego ograniczenia działania badanej mieszaniny, dla obu faz rozwojowych A. arvensis i dawek herbicydu. Biomasa drugiego $\mathrm{z}$ badanych gatunków, tj. $P$. rhoeas, była nieco słabiej redukowana (82\%) niż u $A$. arvensis przez środek w dawce zalecanej, zastosowany w warunkach optymalnych (rys. 4). Aplikacja w dawce obniżonej spowodowała znaczący spadek efektywności do poziomu 45\%. Podobną skuteczność osiągnięto po zastosowaniu herbicydu w dawce

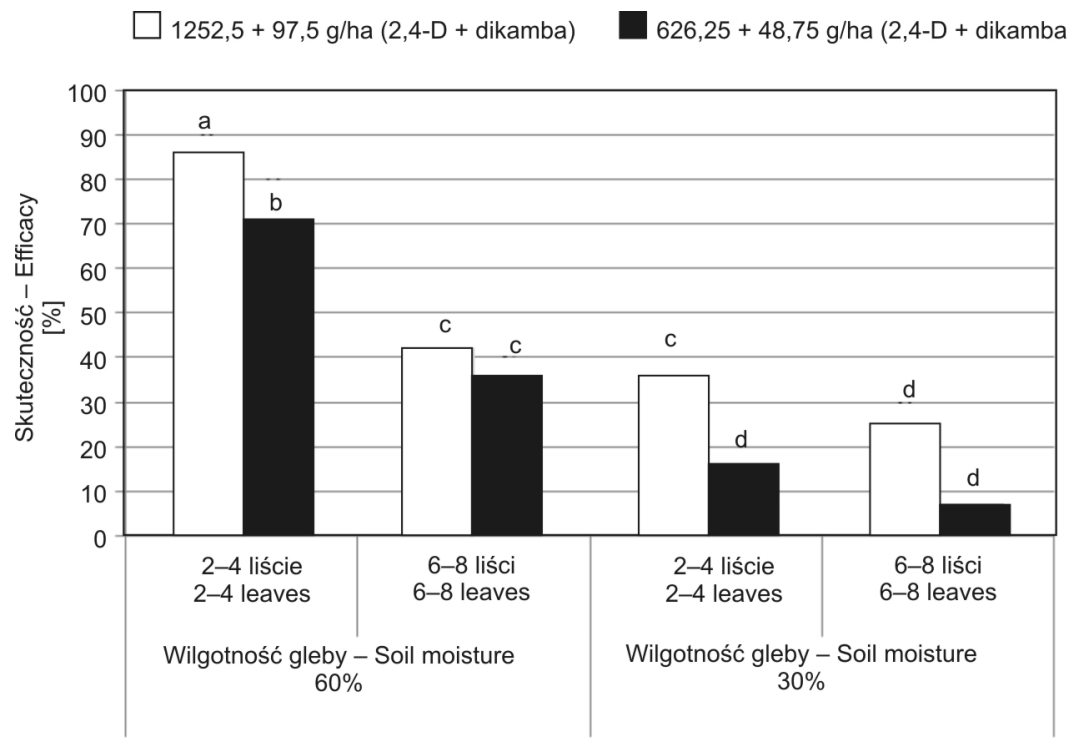

Wartości oznaczone tą samą litera nie różnią się istotnie Values marked by the same letter do not differ significantly

Rys. 3. Wpływ współdziałania wilgotności gleby i fazy rozwojowej na skuteczność mieszaniny 2,4-D + dikamba w zwalczaniu A. arvensis

Fig. 3. Influence of interaction between soil moisture and growth stage on the efficacy of the mixture 2,4-D + dicamba against A. arvensis

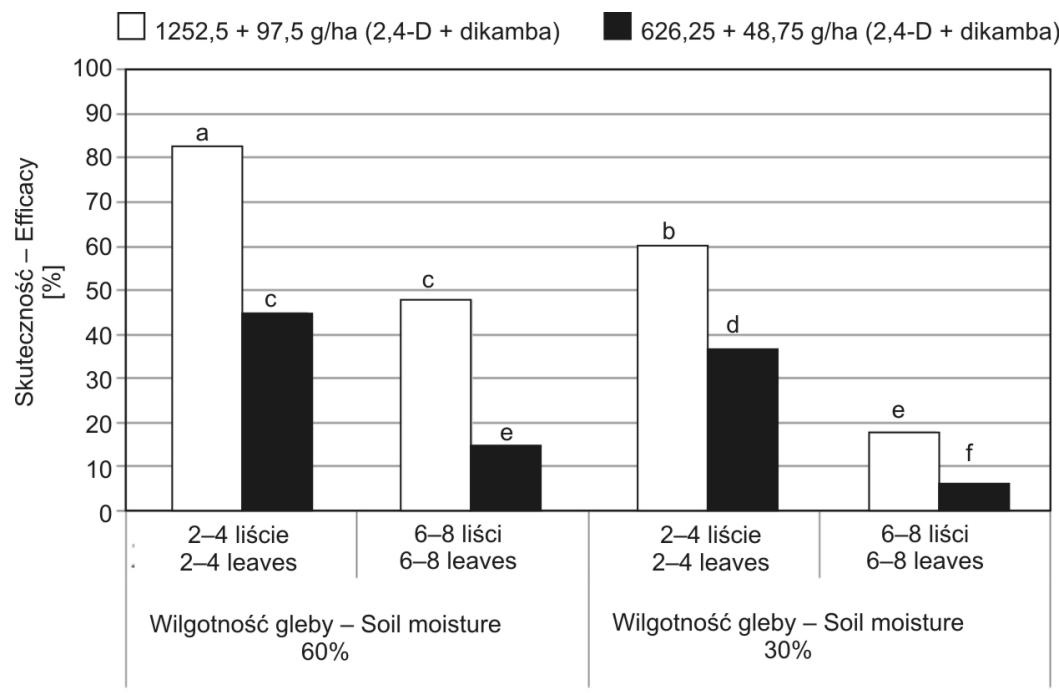

Wartości oznaczone tą samą literą nie różnia się istotnie Values marked by the same letter do not differ significantly

Rys. 4. Wpływ współdziałania wilgotności gleby i fazy rozwojowej na skuteczność mieszaniny 2,4-D + dikamba w zwalczaniu P. rhoeas

Fig. 4. Influence of interaction between soil moisture and growth stage on the efficacy of the mixture 2,4-D + dicamba against P. rhoeas 
podstawowej na rośliny bardziej zaawansowane w rozwoju. Słabe działanie $(60 \%)$ zaobserwowano po aplikacji dawki podstawowej na rośliny rosnące w warunkach słabego uwilgotnienia gleby, nawet gdy znajdowały się one we wczesnej fazie rozwojowej. Efektywność herbicydu znacząco malała wraz z obniżeniem dawki i stopniem zaawansowania roślin w rozwoju, wykazując poziom zniszczenia $P$. rhoeas na poziomie zaledwie $6 \%$ dla dawki obniżonej stosowanej na rośliny w fazie 6-8 liści.

W pracy porównywano działanie dwóch herbicydów, o różnym mechanizmie działania, w warunkach optymalnych pod względem wilgotności gleby i fazy rozwojowej roślin z warunkami mniej korzystnymi dla ich działania. Efekt chwastobójczy mieszaniny 2,4-D + florasulam był w mniejszym stopniu zależny od powyższych czynników niż w przypadku drugiego $\mathrm{z}$ badanych środków. W warunkach optymalnych, tj. gdy aplikację wykonano na rośliny w fazie 2-4 liści rosnące na glebie o wilgotności 60\%, jego działanie było znacznie lepsze w porównaniu z mieszaniną 2,4-D + dikamba, niezależnie od pozostałych czynników. Obserwowany dla obu herbicydów spadek skuteczności na glebie słabo wilgotnej wynikał z reakcji roślin na stres wodny. W warunkach niskiej wilgotności gleby roślina wytwarza cechy zapobiegające utracie wody, tj. grubszą kutikulę, zwija blaszki liściowe (Levene i Owen 1995; Morrison i wsp. 1995). Zjawisko to skutkuje ograniczeniem powierzchni absorpcyjnej roślin, a tym samym ilości substancji czynnej pobranej przez roślinę. Słabszą skuteczność w stosunku do chwastów rosnących na glebie o niskim stopniu uwilgotnienia wykazano również $\mathrm{w}$ innych badaniach, m.in. w przypadku zastosowania fluroksypyru wobec Kochia scoparia (L.) Schrad., fenoksapropu wobec Avena fatua L. czy też glifosatu (Xie i wsp. 1997; Adkins i wsp. 1998; Lubbers i wsp. 2007).

Herbicydy stosowane na chwasty będące we wczesnych fazach rozwojowych są najbardziej skuteczne, jednak niektóre gatunki można $\mathrm{z}$ powodzeniem zwalczyć nawet wtedy, gdy są bardziej zaawansowane w rozwoju (Kieloch i Domaradzki 2011). W przeprowadzonych badaniach oba gatunki były słabiej niszczone, gdy osiągnęły fazę 6-8 liści. Zmniejszona wrażliwość chwastów na herbicydy wynika z faktu, że wraz ze wzrostem i rozwojem roślin ulega zmianie skład chemiczny wosku oraz wzrasta jego ilość, dlatego rośliny słabiej reagują na środki chwastobójcze (Chachalis i wsp. 2001). W innych badaniach wykazano, że grubsza warstwa wosku u roślin starszych prowadzi do redukcji pobierania herbicydu przez roślinę (Cruz-Hipolito i wsp. 2011).

Badania nad określeniem wpływu czynników klimatyczno-glebowych oraz fazy rozwojowej chwastów są istotnym elementem prac w zakresie możliwości obniżania dawek herbicydów, ponieważ w niekorzystnych warunkach środek aplikowany w dawce zredukowanej może wykazywać znacznie słabszy efekt chwastobójczy. W wykonanych badaniach znaczny spadek efektywności herbicydów stosowanych w dawce obniżonej, a zwłaszcza mieszaniny 2,4-D + dikamba, obserwowano w warunkach niesprzyjających działaniu herbicydów, tj. niskiej wilgotności gleby i zaawansowanej fazie rozwojowej chwastów. Podobne rezultaty uzyskał Collings i wsp. (2003) twierdząc, że wpływ przebiegu pogody jest bardziej wyraźny, gdy herbicydy stosuje się w dawkach niższych niż zalecane.

Skuteczność herbicydu może być znacznie ograniczona jeśli podlega ona negatywnemu wpływowi więcej niż jednego czynnika. W warunkach niskiej wilgotności gleby pobieranie herbicydu może być znacznie zredukowane, gdy stosuje się go na chwasty bardziej zawansowane w rozwoju, co skutkuje słabszym efektem chwastobójczym (Ahmadi i wsp. 1980). W prowadzonych badaniach zaobserwowano również wpływ interakcji wilgotności gleby i fazy rozwojowej chwastów na efektywność herbicydów, jednak bardziej wyraźny był on w przypadku dawki zredukowanej.

\section{Wnioski / Conclusions}

1. W warunkach optymalnych, tj. gdy zabieg wykonano na rośliny w fazie 2-4 liści, rosnace na glebie o wilgotności $60 \%$, osiągnięto wysoką skuteczność obu dawek mieszaniny 2,4-D + florasulam oraz zalecanej dawki mieszaniny 2,4-D + dikamba, a jej obniżenie przyczyniło się do słabszego zwalczania chwastów.

2. Niska wilgotność gleby i zaawansowana faza rozwojowa chwastów przyczyniła się do słabszego działania mieszaniny 2,4-D + florasulam w stosunku do $P$. rhoeas. W przypadku stosowania środka na $A$. arvensis, nie wykazano niekorzystnego wpływu niskiej wilgotności gleby na skuteczność herbicydu jedynie w przypadku, gdy rośliny znajdowały się w fazie 2-4 liści.

3. Mieszanina 2,4-D + dikamba aplikowana w optymalnych warunkach była wysoce skuteczna jedynie w niszczeniu $A$. arvensis. Niezależnie od gatunku chwastu, w powyższych warunkach nastąpił spadek skuteczności herbicydu stosowanego w dawce zredukowanej.

4. Aplikacja mieszaniny $2,4-\mathrm{D}+$ dikamba na rośliny $\mathrm{w}$ fazie 6-8 liści skutkowała słabym efektem chwastobójczym bez względu na wilgotność gleby. Do znacznego spadku skuteczności przyczynił się również deficyt wody w glebie.

Opracowanie wykonano $\mathrm{w}$ ramach zadania $2.6 \mathrm{w}$ programie wieloletnim Instytutu Uprawy Nawożenia i Gleboznawstwa - Państwowego Instytutu Badawczego.

\section{Literatura / References}

Adkins S.W., Tanpipat S., Swarbrick J.T., Boersma M. 1998. The influence of soil moisture content on glyphosate efficacy for the control of annual grasses in fallow land. Weed Research 38 (2): 119-127.

Ahmadi M.S., Haderlie L.C., Wicks G.A. 1980. Effect of growth stage and water stress on barnyardgrass (Echinochloa crus-galli) control and on glyphosate absorption and translocation. Weed Science 28: 277-282. 
Chachalis D., Reddy K.N., Elmore C.D. 2001. Characterization of leaf surface, wax composition, and control of redvine and trumpetcreeper with glyphosate. Weed Science 49 (2): 156-163.

Collings L.V., Blair A.M., Gay A.P., Dyer C.J., Mackay N. 2003. The effect of weather factors on the performance of herbicides to control Alopecurus myosuroides in winter wheat. Weed Research 43: 146-153.

Cruz-Hipolito H., Osuna M.D., Domínguez-Valenzuela J., Espinoza N., De Prado R. 2011. Mechanism of resistance to ACCaseinhibiting herbicides in wild oat (Avena fatua) from Latin America. Journal of Agricultural and Food Chemistry 59: $7261-7267$.

Domaradzki K., Rola H. 2001. Ekologiczno-agronomiczne aspekty stosowania niższych dawek herbicydów w regulacji zachwaszczenia zbóż. [Ecological and agronomic aspects of application lower rates of herbicides in regulation of weed infestation of cereals]. Progress in Plant Protection/Postępy w Ochronie Roślin 41 (1): 229-239.

Kieloch R., Domaradzki K. 2011. The role of the growth stage of weeds in their response to reduced herbicide doses. Acta Agrobotanica 64 (4): 259-266.

Lubbers M.D., Stahlman P.W., Al.-Khatib K. 2007. Fluroxypyr efficacy is affected by relative humidity and soil moisture. Weed Science 55 (3): 260-263.

Levene B.C., Owen M.D.K. 1995. Effect of moisture stress and leaf age on bentazon absorption in common cocklebur (Xantium strumarium) and velvetleaf (Abutilon theoprasti). Weed Science 43 (1): 7-12.

Morrison R.G., Lownds N.K., Steerling T.M. 1995. Picloram uptake, translocation and efficacy in relation to water status of russian knapweed (Acroptilon repens). Weed Science 43 (1): 34-39.

Petersen J., Hurle K. 2001. Influence of climatic conditions and plant physiology on glufosinate-ammonium efficacy. Weed Research 41 (1): 31-39.

Urban M., Gil Z., Smorąg A., Grządka M. 2011. Wpływ zróżnicowanych dawek herbicydów na redukcję zachwaszczenia i plonowanie odmian pszenicy jarej. [The effect of varied herbicide doses on weed infestation and yielding of spring wheat varieties]. Progress in Plant Protection/Postępy w Ochronie Roślin 51 (2): 707-713.

Xie H.S., Hsiao A.I., Quick W.A. 1997. Influence of drought on graminicide phytotoxicity in Wild oat (Avena fatua) grown under different temperature and humidity conditions. Journal of Plant Growth Regulation 16 (4): 233-237. 